\title{
(2) \\ Using absolute risk reduction to guide the equitable distribution of COVID-19 vaccines
} OPEN ACCESS

\author{
Ella Fassler (1) , ${ }^{1}$ Andrew Larkin (1), ${ }^{1}$ \\ Kesavan Rajasekharan Nayar 다 , 2,3 Howard Waitzkin (1) 1,4
}

10.1136/bmjebm-2021-111789

${ }^{1}$ Allende Program in Social Medicine, Albuquerque, New Mexico, USA

${ }^{2}$ Global Institute of Public Health, Thiruvananthapuram, Kerala, India

${ }^{3}$ Santhigiri Research

Foundation,

Thiruvananthapuram, Kerala, India

${ }^{4}$ Locum Tenens Program, Health Sciences Center; and Department of Sociology, University of New Mexico, Albuquerque, New Mexico, USA

Correspondence to: Dr Howard Waitzkin, University of New Mexico Health Sciences Center, 801 Encino Place NE, Albuquerque, New Mexico 87102, Albuquerque, New Mexico 87102, USA; waitzkin@unm.edu

\section{Check for updates}

( $)$ Author(s) (or their employer(s)) 2022. Re-use permitted under CC BY-NC. No commercial re-use. See rights and permissions. Published by BMJ.

To cite: Fassler E, Larkin A, Rajasekharan Nayar K, et al. BMJ Evidence-Based Medicine Epub ahead of print: [please include Day Month Year]. doi:10.1136/ bmjebm-2021-111789

\section{Introduction}

Massive economic inequality, poverty and structural racism, in addition to intellectual property laws and regulations, are creating the conditions for gaping inequities in COVID-19 vaccine distribution. Journalists, activists and public health practitioners have characterised the largely preventable public health crisis as vaccine apartheid. At the time of this writing (January 2022), just $9.7 \%$ of people in lower-income countries had received at least one shot of the COVID-19 vaccine, compared with $60.6 \%$ globally. ${ }^{1}$ Vaccine inequities have also been observed within multiple countries such as India and South Africa. ${ }^{23}$

Efforts to bridge the gaps are largely failing. In April 2021, with input from the World Bank and consultants including McKinsey \& Company, the WHO and other allied organisations launched the COVID-19 Global Access initiative (COVAX), in a stated attempt to address vaccine inequity by facilitating the global coordination of vaccine production and distribution. ${ }^{4}$ But COVAX is doing little to challenge the intellectual property regime or power of pharmaceutical companies and the World Bank. Wealthier countries are hoarding vaccines by placing advance orders for hundreds of millions of doses at the expense of poorer countries. As a result, many may not be able to vaccinate the majority of their populations until $2024 .^{5}$

Without major structural changes to the global economic order, health inequities related to vaccination are likely to remain a grim reality. In this context, public health researchers, policymakers and other stakeholders could help generate evidence-based vaccine distribution strategies and identify barriers that prevent these strategies from being enacted.

\section{Effect measures and vaccine distribution}

Public health systems can prioritise vulnerable populations for vaccination. Many countries are already prioritising healthcare workers and the elderly, but more specificity may be needed to reduce hospitalisation, severe disease and death. Vaccine distribution programmes and outreach efforts could prioritise subpopulations in geographical areas with high baseline risk during an outbreak, for example, instead of subpopulations in areas with lower baseline risk.

Several key effect measures, including absolute risk reduction (ARR) and the number needed to be treated or number needed to be vaccinated (NNV), are well-suited for this task. ARR and NNV are more helpful than relative measures such as relative risk reduction (RRR), for assessing the effect of a treatment or a preventative programme like vaccination in populations with differing baseline risks. ${ }^{6-10} \mathrm{NNV}$ is estimated from the incidence of a certain event in the unvaccinated population and estimates of vaccine effectiveness (VE): $(\mathrm{NNV}=1 / \mathrm{ARR}=1$ /incidence of event in the unvaccinated $\times \mathrm{VE})$.

Some researchers have raised concerns that the targets for NNV in prior vaccination programmes are variable, dynamic, context-specific and may not capture the effects of vaccination on transmission and herd immunity. ${ }^{11-13}$ Considering that a substantial proportion of fully vaccinated individuals still can transmit COVID-19 to others, achieving heard immunity remains unlikely. ${ }^{14}$

Meanwhile, understanding that the effectiveness of vaccination, estimated by ARR and NNV, can vary in population subgroups with different baseline risks can facilitate policies about vaccine distribution. For instance, studies of influenza and pertussis vaccines in Sweden and Canada have led to differing policy recommendations about vaccine distribution for population subgroups located in geographical areas with varying baseline risks. ${ }^{15} 16$ The Advisory Committee on Immunization Practices of the US Centers for Disease Control and Prevention (CDC) cites absolute vaccine efficacy data in its report on influenza immunisation practices and communicates benefits and harms associated with human papilloma virus. ${ }^{17} 18$

While randomised controlled trials and population-based assessments do not routinely report ARR or NNV, their main effect measure for vaccine effectiveness is RRR. Some researchers have subsequently calculated ARR and NNV using data from major studies, but none has assessed the metrics across subpopulations. ${ }^{19}$

\section{Dynamically reporting key absolute effect measures}

To facilitate policies about vaccine distribution, public health researchers could perform continuing analyses that consider ARR and NNV in population subgroups, including across socioeconomic groupings, with differing baseline risks of disease. Researchers could obtain baseline risks from available public data and re-run analyses frequently.

To illustrate, we calculated the ARR and NNV within several states and territories in the USA and India related to our work in public health (table 1). 


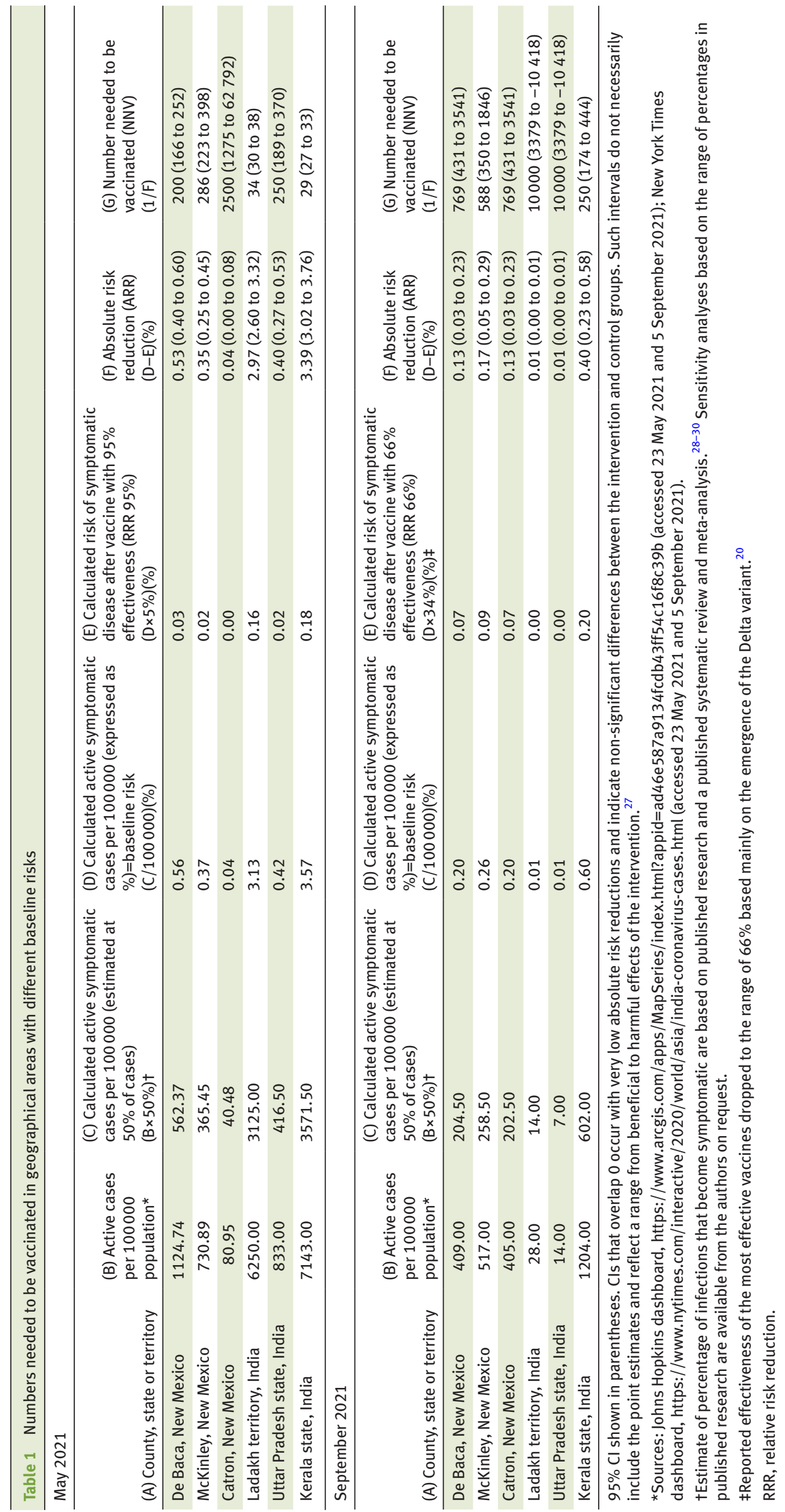


During May 2021 in New Mexico, De Baca County with a large proportion of Latinx low-income residents and McKinley County with a large proportion of Navajo low-income residents would have been prioritised for vaccine distribution compared with Catron County with a mostly white, higher income population. In India, Kerala state and Ladakh territory would have received prioritisation, compared with Uttar Pradesh state. Later, during September 2021, with vaccine effectiveness reduced to $66 \%$ due to the Delta variant, ${ }^{20}$ the ARRs and NNVs again varied substantially, linked to variations in baseline risks. McKinley County, New Mexico, would have been prioritised, but the prioritisation of De Baca and Catron counties would not have differed substantially. In India, overall, the ARRs decreased and NNVs increased. Based on available data, Kerala state again would have received prioritisation.

\section{Barriers to adopting these metrics}

Despite potential benefits of using these indicators to guide vaccine distribution, such an approach may prove challenging in some countries. For example, in India the federal and some state governments made certain decisions about vaccine distribution based on a framework known as 'eminence-based' medicine. ${ }^{21}$ Some public health agencies withheld data from the public and did not assess baseline risk across socioeconomic groupings. ${ }^{22}$ In the USA, the CDC tracked vaccination status with demographic data, ${ }^{23}$ but it did not use ARR or NNV to guide vaccine distribution policies. Many US states and counties struggled to track COVID-19 cases. $^{24}$

Calculating and updating ARR and NNV across subpopulations require some investment of time and resources. A region's baseline risk calculation depends on its ability to detect cases and testing capacity. In addition to waiving intellectual property laws and providing technological assistance for vaccine production, wealthier countries could fund data collection in lower-income counties and countries. Understanding the evidence more fully, of course, does not necessarily lead to policy decisions that the evidence suggests, but it may provide some leverage for people to advocate for their own health.

Patients and the public should be provided with transparent information about ARR in addition to RRR for population subgroups, as well as an overview of benefits versus harms. If a vaccine helps reduce transmission or enhances herd immunity, these effects should be quantified and explained clearly to patients and the public. Especially for individuals in population subgroups with higher baseline risks, educational efforts may emphasise the likely greater effectiveness of vaccines than in population subgroups with lower baseline risks.

A similar approach could guide vaccine distribution for subsequent waves, such as that dominated by the Omicron variant, as well as policies about booster vaccinations. Such guidance would depend on the observed baseline risks in different population subgroups, the observed RRR of vaccines against new variants and the varying calculated ARR for different population subgroups.

\section{Guiding an equitable distribution of vaccines}

Low-income countries have taken on increased debt and other financial burdens because of intellectual property laws; high prices charged by pharmaceutical companies and vaccine hoarding by wealthier countries, in what has been called vaccine apartheid. ${ }^{25}$ A strategy emphasising vaccines' differential impacts on reducing absolute risk in population subgroups with varying baseline risks could alleviate some economic and practical burdens of trying to provide vaccines for everyone, especially in poorer regions of richer countries, or in regions of poorer countries in the Global South.

Public health systems can assess baseline risks to target dynamically 'hot spot' areas for vaccine distribution. While not in any way justifying unequal access to vaccines, this strategy becomes especially important as we face the reality of barriers related to wealth, power, minority status, structural racism and other sources of profound inequality-conditions that create vaccine apartheid, as part of the broader social determination of health. ${ }^{26}$

Contributors AL conceptualised the study, with input from HW. AL coordinated the statistical analysis and literature reviews, with inputs from HW. AL wrote the first draft of the manuscript; HW did extensive revisions; EF reorganised and extensively revised the manuscript in response to suggestions from the editor-in-chief, peer reviewers and an associate editor; and KRN and HW did further revisions. All coauthors approved the final version of the manuscript. The corresponding author attests that all listed authors meet authorship criteria and that no others meeting the criteria have been omitted. HW is the guarantor.

Funding EF is an independent journalist who received partial financial compensation from the Allende Program in Social Medicine for work on this project. No other specific funding was received for this study. AL and HW are semi-retired from clinical practice in internal medicine. HW receives access to library resources and personnel, internet service and uses of other facilities as a distinguished professor emeritus at the University of New Mexico. HW obtains no ongoing salary support but does receive retirement pensions as an emeritus professor from the University of New Mexico and the University of California. HW also receives payments as a primary care practitioner working to cover rural community health centres through the University of New Mexico's Locum Tenens Program. $\mathrm{AL}$ receives a retirement pension from a private fund generated through his medical practice. Employers/sponsors had no role in the design, analysis or dissemination of the study. The views expressed in this article are those of the authors and not necessarily those of the entities the authors are affiliated with and/or supported by.

Competing interests All authors have completed the ICMJE uniform disclosure form at www.icmje.org/coi_disclosure.pdf and declare: except as noted above, no specific funding was received for this study. From personal earnings based on past and present clinical work, AL and HW make financial contributions to the Allende Program in Social Medicine, a tax-exempt charitable foundation, which provides support for projects in social medicine. The Allende Program in Social Medicine received a grant from the James R and Mary Jane Barrett Foundation, Baltimore, Maryland, USA, for a clinical programme serving active-duty military personnel that HW directs and that is unrelated to the present report. HW and AL receive royalties and honorariums for books, other writings and presentations for universities and non-profit organisations unrelated to this project. EF receives payments from publications that publish their articles. No other relationships or activities could appear to have influenced the submitted work.

Patient consent for publication Not applicable.

Ethics approval This study does not involve human participants.

Provenance and peer review Not commissioned; externally peer reviewed. 
Open access This is an open access article distributed in accordance with the Creative Commons Attribution Non Commercial (CC BY-NC 4.0) license, which permits others to distribute, remix, adapt, build upon this work non-commercially, and license their derivative works on different terms, provided the original work is properly cited, appropriate credit is given, any changes made indicated, and the use is non-commercial. See: http://creativecommons.org/licenses/by-nc/4.0/.

\section{ORCID iDs}

Ella Fassler http://orcid.org/0000-0001-5299-536X

Andrew Larkin http://orcid.org/0000-0003-2214-0031

Kesavan Rajasekharan Nayar http://orcid.org/0000-0003-42031959

Howard Waitzkin http://orcid.org/0000-0001-5084-6117

\section{References}

1 Our World in Data. Coronavirus (COVID-19) vaccinations. Available: https://ourworldindata.org/covid-vaccinations [Accessed 28 Jan 2022].

2 Mehrotra N, Saaliq S. Vaccine inequality in India sends many falling through gaps, 2021. AP News. Available: https://apnews.com/article/indiatechnology-coronavirus-pandemic-business-health-9fc262598b4a6e1fc5ff 223fdd748cea [Accessed 6 Dec 2021].

3 Bowker J, Siwele K. Inequality legacy haunts South Africa's vaccine rollout plan, 2021. Bloomberg. Available: https://www.bloomberg.com/ news/articles/2021-06-08/inequality-legacy-haunts-south-africa-svaccine-rollout-plan [Accessed 6 Dec 2021]

4 The White House. Global Covid-19 Summit: ending the pandemic and building back better, 2021. Available: https://www.whitehouse.gov/ briefing-room/statements-releases/2021/09/24/global-covid-19-summitending-the-pandemic-and-building-back-better/ [Accessed 6 Dec 2021].

5 Lerner S. World faces Covid-19 “vaccine apartheid.”, 2020. The Intercept. Available: https://theintercept.com/2020/12/31/covid-vaccine-countriesscarcity-access/ [Accessed 6 Dec 2021].

6 Fagerlin A, Peters E. Quantitative information. In: Fischhoff B, Brewer NT, Downs JS, eds. Communicating risks and benefits: an evidence-based user's guide. Washington DC: US Food and Drug Administration, 2011: 60 https://www.fda.gov/media/81597/download

7 Straus SE, Glasziou P, Richardson WS. Evidence-based medicine: how to practice and teach EBM. 90. Edinburgh: Elsevier, 2019.

$8 \mathrm{BMJ}$ guidance for authors. Available: https://drive.google.com/file/d/1lh9 zzpFUUoOuLVszt4kB8jMv097nfJTn/view [Accessed 14 Dec 2021].

9 BMJ Evidence-Based Medicine. Submission guidelines for authors. Available: https://ebm.bmj.com/pages/authors/\# original_research [Accessed 14 Dec 2021].

10 Laupacis A, Sackett DL, Roberts RS. An assessment of clinically useful measures of the consequences of treatment. $N$ Engl J Med 1988;318:1728-33.

11 Hashim A, Dang V, Bolotin S, et al. How and why researchers use the number needed to vaccinate to inform decision making--a systematic review. Vaccine 2015;33:753-8.

12 McLaughlin JM, Swerdlow DL, Isturiz RE, et al. Rethinking numberneeded-to-vaccinate for pneumococcal conjugate vaccines in older adults: current and future implications. Vaccine 2017;35:5360-5.
13 Tuite AR, Fisman DN. Number-needed-to-vaccinate calculations: fallacies associated with exclusion of transmission. Vaccine 2013;31:973-8.

14 Dyer 0. Covid-19: delta infections threaten herd immunity vaccine strategy. BMJ 2021;374:n1933.

15 Merk H, Nylén G, Kühlmann-Berenzon S, et al. Number needed to vaccinate to prevent hospitalizations of pregnant women due to interpandemic influenza in Sweden, 2003-2009. Vaccine 2014;32:7135-40.

16 Skowronski DM, Janjua NZ, Tsafack EPS, et al. The number needed to vaccinate to prevent infant pertussis hospitalization and death through parent cocoon immunization. Clin Infect Dis 2012;54:318-27.

17 Grohskopf LA, Alyanak E, Broder KR, et al. Prevention and control of seasonal influenza with vaccines: recommendations of the Advisory Committee on Immunization Practices - United States, 2020-21 Influenza Season. MMWR Recomm Rep 2020;69:1-24.

18 Advisory Committee on Immunization Practices (ACIP), Centers for Disease Control and Prevention. ACIP evidence to recommendations framework. question 2: should catch-up HPV vaccination be recommended for primary prevention of HPV infection and HPV-related disease for all persons ages 27 through 45 years? 2019. Available: https:// www.cdc.gov/vaccines/acip/recs/grade/HPV-adults-etr-H.pdf [Accessed 3 Sep 2021].

19 Larkin A, Waitzkin H. COVID-19 vaccines and evidence-based medicine, 2021. Available: medRxiv.org.

20 Fowlkes A, Gaglani M, Groover K, et al. Effectiveness of COVID-19 vaccines in preventing SARS-CoV-2 infection among frontline workers Before and during B.1.617.2 (Delta) variant predominance - eight U.S. locations, December 2020-August 2021. MMWR Morb Mortal Wkly Rep 2021;70:1167-9.

21 Nayar KR. Critical reflections on health services development in India. 41. Lanham, MD: Lexington Books, 2014.

22 Vasudevan V, Gnanasekaran A, Sankar V, et al. Disparity in the quality of COVID-19 data reporting across India. BMC Public Health 2021;21:1211.

23 Centers for Disease Control and Prevention. Vaccination demographic data, 2021. Available: https://www.cdc.gov/coronavirus/2019-ncov/ vaccines/distributing/demographics-vaccination-data.html [Accessed 6 Dec 2021].

24 Banco E. Inside America’s Covid-reporting breakdown, 2021. Politico. Available: https://www.politico.com/news/2021/08/15/inside-americascovid-data-gap-502565 [Accessed 14 Dec 2021].

25 Hassan F, Yamey G, Abbasi K. Profiteering from vaccine inequity: a crime against humanity? BMJ 2021;374:n2027.

26 Waitzkin H, Pérez A, Anderson M. Social medicine and the coming transformation. New York: Routledge, 2021: 79-108.

27 Altman DG. Confidence intervals for the number needed to treat. BMJ 1998;317:1309-12.

28 Oran DP, Topol EJ. Prevalence of asymptomatic SARS-CoV-2 infection: a narrative review. Ann Intern Med 2020;173:362-7.

29 Yanes-Lane M, Winters N, Fregonese F, et al. Proportion of asymptomatic infection among COVID-19 positive persons and their transmission potential: a systematic review and meta-analysis. PLoS One 2020;15:e0241536.

30 Sah P, Fitzpatrick MC, Zimmer CF, et al. Asymptomatic SARS-CoV-2 infection: a systematic review and meta-analysis. Proc Natl Acad Sci U S A 2021;118:e2109229118. 